\title{
Molecular Characterization of a Novel Lytic Enzyme LysC from Clostridium intestinale URNW and Its Antibacterial Activity Mediated by Positively Charged $N$-Terminal Extension
}

\author{
Magdalena Plotka 1,*(D), Monika Szadkowska ${ }^{1}$, Maria Håkansson ${ }^{2}$, Rebeka Kovačič ${ }^{2}$, \\ Salam Al-Karadaghi ${ }^{2}$, Björn Walse ${ }^{2}$, Olesia Werbowy ${ }^{1}$, Anna-Karina Kaczorowska ${ }^{3}$ \\ and Tadeusz Kaczorowski ${ }^{1, *(1)}$ \\ 1 Laboratory of Extremophiles Biology, Department of Microbiology, Faculty of Biology, University of Gdansk, \\ 80-822 Gdansk, Poland; monika.szadkowska@phdstud.ug.edu.pl (M.S.); olesia.werbowy@ug.edu.pl (O.W.) \\ 2 SARomics Biostructures, SE-223 81 Lund, Sweden; maria.hakansson@saromics.com (M.H.); \\ rebkova@gmail.com (R.K.); salam.al-karadaghi@saromics.com (S.A.-K.); bjorn.walse@saromics.com (B.W.) \\ 3 Collection of Plasmids and Microorganisms, Faculty of Biology, University of Gdansk, 80-308 Gdansk, \\ Poland; anna.kaczorowska@ug.edu.pl \\ * Correspondence: magdalena.plotka@ug.edu.pl (M.P.); tadeusz.kaczorowski@ug.edu.pl (T.K.)
}

Received: 19 June 2020; Accepted: 7 July 2020; Published: 11 July 2020

Abstract: Peptidoglycan hydrolytic enzymes are considered to be a promising alternative to conventional antibiotics in combating bacterial infections. To identify novel hydrolytic enzymes, we performed a database search with the sequences of two thermostable endolysins with high bactericidal activity, studied earlier in our laboratory. Both these enzymes originate from Thermus scotoductus bacteriophages MAT2119 and vB_Tsc2631. A lytic enzyme LysC from Clostridium intestinale URNW was found to have the highest amino acid sequence similarity to the bacteriophage proteins and was chosen for further analysis. The recombinant enzyme showed strong activity against its host bacteria C. intestinale, as well as against C. sporogenes, Bacillus cereus, Micrococcus luteus, and Staphylococcus aureus, on average causing a $5.12 \pm 0.14 \log$ reduction of viable S. aureus ATCC 25923 cells in a bactericidal assay. Crystallographic studies of the protein showed that the catalytic site of LysC contained a zinc atom coordinated by amino acid residues $\mathrm{His}^{50}, \mathrm{His}^{147}$, and Cys ${ }^{155}$, a feature characteristic for type 2 amidases. Surprisingly, neither of these residues, nor any other of the four conserved residues in the vicinity of the active site, $\mathrm{His}^{51}, \mathrm{Thr}^{52}$, $\mathrm{Tyr}^{76}$, and $\mathrm{Thr}^{153}$, were essential to maintain the antibacterial activity of LysC. Therefore, our attention was attracted to the intrinsically disordered and highly positively charged $N$-terminal region of the enzyme. Potential antibacterial activity of this part of the sequence, predicted by the Antimicrobial Sequence Scanning System, AMPA, was confirmed in our experimental studies; the truncated version of LysC (LysC $\Delta 2-23$ ) completely lacked antibacterial activity. Moreover, a synthetic peptide, which we termed Intestinalin, with a sequence identical to the first thirty amino acids of LysC, displayed substantial anti-staphylococcal activity with $\mathrm{IC}_{50}$ of $6 \mu \mathrm{g} / \mathrm{mL}(1.5 \mu \mathrm{M})$. This peptide was shown to have $\alpha$-helical conformation in solution in the presence of detergents which is a common feature of amphipathic $\alpha$-helical antimicrobial peptides.

Keywords: bacteriophage; endolysin; autolysin; antimicrobial peptide; peptidoglycan; Staphylococcus aureus; thermophiles 


\section{Introduction}

The discovery and introduction of antibiotics, starting with penicillin, made a revolutionary change in the way of treating bacterial infections. However, despite unquestionable benefits associated with new therapies, it was immediately observed that microorganisms quickly start to develop resistance to antibiotics and bacterial infections again become a serious threat to human life. Therefore, as the antibiotic pipeline was beginning to dry up, an urgent need emerged for novel antimicrobial agents, capable of combatting multidrug-resistant pathogens. Among the most promising alternatives to conventional antibiotics are peptidoglycan hydrolytic enzymes. Peptidoglycan (PG) is a major constituent of the bacterial cell wall with a function to protect cells from bursting due to high internal turgor pressure that can reach up to $30 \mathrm{~atm}$ in Gram-positive bacteria [1]. PG is built up by linear glycan strands, made up of $N$-acetylglucosaminyl- $N$-acetylmuraminyl disaccharide repeats, cross-linked by short peptide stems that together form a mesh-like structure around the bacterial cytoplasmic membrane [2]. Bacterial peptidoglycan hydrolases can be classified into three groups depending on which covalent bonds they specifically cleave in the polymer or in its soluble fragments. Amidases cleave the amide bond connecting the stem-peptide to the glycan backbone of PG, glycosidases ( $\mathrm{N}$-acetylglucosaminidases and $\mathrm{N}$-acetylmuramidases) catalyze the hydrolysis of the glycosidic linkages, whereas peptidases cleave amide bonds between amino acids in the PG chain [3]. Based on their origin and role, peptidoglycan hydrolases can be categorized into endolysins, exolysins, and autolysins [4]. Endolysins are produced near the end of the lytic cycle of bacteriophages. They enzymatically degrade peptidoglycan 'from within', leading to lysis of the bacterial cell and release of phage progeny [5]. Exolysins are produced and secreted by certain bacteria to fight alien bacterial species. Examples include lysostaphin, a bacteriocin secreted by Staphylococcus simulans that targets S. aureus, including methicillin-resistant strains. Representatives of the third group, autolysins, cleave the peptidoglycan of bacteria that produce them. They are mainly involved in cellular processes, including cell growth and division, cell-wall turnover, and peptidoglycan maturation.

The functional classification of endolysins, exolysins, and autolysins, and their designation as amidases, glycosidases or peptidases, depends on the structural organization of an individual protein. Amidases, also known as $\mathrm{N}$-acetylmuramoyl-L-alanine amidases, have three different types of catalytic domains: (i) Amidase_2 (family: PF01510), (ii) Amidase_3 (family: PF01520), and (iii) Amidase_5 (family: PF05382) [6]. The family of type 2 amidases includes zinc amidases, a representative of which is bacteriophage T7 lysozyme. This enzyme contains two conserved histidine residues, His ${ }^{17}$ and $\mathrm{His}^{122}$, and one cysteine $\mathrm{Cys}^{130}$ which coordinate a zinc atom [7]. Recently, our group discovered two thermostable endolysins derived from T. scotoductus bacteriophages MAT2119 and vB_Tsc2631. Both, Ph2119 and Ts2631 endolysins cleaved PG not only of thermophiles but also of mesophilic Gram-negative bacteria including Escherichia coli, Salmonella serovar Panama, Serratia marcescens, and Pseudomonas fluorescens [8,9]. However, all of the above mesophilic bacteria, before the addition of the endolysin, were treated with chloroform-saturated Tris-HCl buffer in order to permeabilize their outer membranes, which serve as a natural barrier that prevents endolysin from reaching and digesting the PG layer [10]. The difficulties associated with bypassing the outer membrane of Gram-negative bacteria for many years hindered the extracellular use of endolysins as antibacterial agents. Presently, human-safe, outer membrane permeabilizers such as a cation chelator ethylenediaminetetraacetic acid (EDTA) or weak organic acids, such as citric acid and malic acid, are used to enhance endolysin activity against Gram-negative bacteria [11]. An alternative approach to the use of permeabilizing agents is the fusion of a lytic enzyme of interest with a short peptide with membrane-penetrating capabilities.

Using molecular engineering techniques, it has already been possible to design several of such chimeric lytic enzymes. This was achieved by the addition of highly cationic nonapeptide (PCNP; a mixture of arginine and lysine residues) to OBPgp279 endolysin, which provided it with high antibacterial activity against $P$. aeruginosa [12]. The enhancement of bacteriolytic activity was also possible in the case of endolysins of Gram-positive origin. A chimeric endolysin Art-240, encompassing a fusion of the peptide PCNP with the $C$-terminus of endolysin from Streptococcus agalactiae prophage 
$\lambda \mathrm{Sa} 2$, showed an increased bactericidal activity against several streptococcal species in relation to the parental enzyme [13].

There are also examples of endolysins with natural antibacterial activity. These include recently discovered Ts2631 endolysin from thermophilic phage isolated from extreme habitat, which shows antibacterial activity against the Gram-negative pathogens, Acinetobacter baumannii and Pseudomonas aeruginosa [14]. In this case, the outer membrane permeabilization was mediated by the $N$-terminal extension of the protein that contains seven basic residues (six arginine and one lysine residues) within the first 20 amino acids.

In this study, we performed a sequence similarity search of the GenBank database to identify lytic enzymes similar to the thermostable Ph2119 and Ts2631 endolysins. From several protein candidates with a predicted lytic function, protein LysC from $C$. intestinale URNW was selected for further analysis. Here, we confirm its lytic activity against several Gram-positive bacterial species including Staphylococcus aureus. Upon LysC treatment, a typical lysis of staphylococcal cells, accompanied with cytoplasmic content leakage was observed under an electron microscope, together with abnormal septum formation and extensive accumulation of membranes in many cells. Crystallographic and site-directed mutagenesis studies reveal that the highly positively charged $N$-terminal region of the protein is the major contributor to the antimicrobial activity of LysC. This finding is also supported by bioinformatics analysis and other experimental data. A 30 amino acids peptide, which we termed Intestinalin, designed and synthetized based on the sequence of the $\mathrm{N}$-terminal region of LysC, was shown to have high antibacterial activity against S. aureus ATCC 25923. This discovery paves the way for the development of a new class of agents with superb antibacterial activity.

\section{Results}

\subsection{Bioinformatics}

The basic local alignment search tool (BLASTP) sequence-similarity searches for proteins showing homology to eukaryotic peptidoglycan recognition proteins (PGRPs) and thermostable Ph2119 and Ts2631 endolysins allowed to identify in the genome of Clostridium intestinale URNW (accession no APJA01000012.1) an open reading frame (ORF, coordinates 584335-584853 nt) encoding a 172 aa protein $\left(\mathrm{M}_{\mathrm{r}}=20,090 ; \mathrm{pI}=9.96\right)$ with a putative lytic function. The enzyme (accession no ERK30183.1) shows $34 \%$ amino acid sequence identity (E value 5e-21) to the thermostable Ph2119 endolysin from Thermus scotoductus bacteriophage MAT2119 and 33\% identity (E value 6e-19) to the Ts2631 endolysin from T. scotoductus bacteriophage vB_Tsc2631. Both lytic enzymes were analyzed in detail in our laboratory $[8,9,14,15]$. The LysC protein also resembles a putative lysozyme from Thermus thermophilus bacteriophage PhiKo (AYJ74695.1), several $N$-acetylmuramoyl-L-alanine amidases (EC: 3.5.1.28) from various Clostridium species including C. perfringens (PWX13837.1) and eukaryotic recognition proteins, PGRPs. BLASTP analysis indicates that LysC contains a conserved $\mathrm{N}$-acetylmuramoyl-L-alanine amidase domain, and similarly to Ph2119 endolysin, belongs to the PGRP family (accession cd06583). However, unlike the thermostable endolysin, LysC also gives a specific hit to the AmpD family (accession COG3023), which groups $\mathrm{N}$-acetyl-anhydromuramyl-L-alanine amidases involved in cell wall/membrane/envelope biogenesis [16,17]. The alignment of the amino acid sequences of the LysC, thermostable endolysins, $\mathrm{N}$-acetylmuramoyl-L-alanine amidase from $\mathrm{C}$. perfringens, and representatives of eukaryotic PGRPs, is shown in Figure 1. In the figure, red arrows highlight the invariant residues of the characteristic endolysin motifs-the HHTAG motif in the N-terminal region, IGYH motif in the middle, and $T(X) C P G$ motif in the $C$-terminal part, where variable $X$ represents glutamic acid (E), threonine (T), or lysine (K) residues in sequences of LysC/Ts2631, Ph2119, and PhiKo lysozyme, respectively. The resemblance of unexplored $\mathrm{LysC}$ to endolysins with high antibacterial potential makes the protein an interesting experimental model for detailed analysis. 


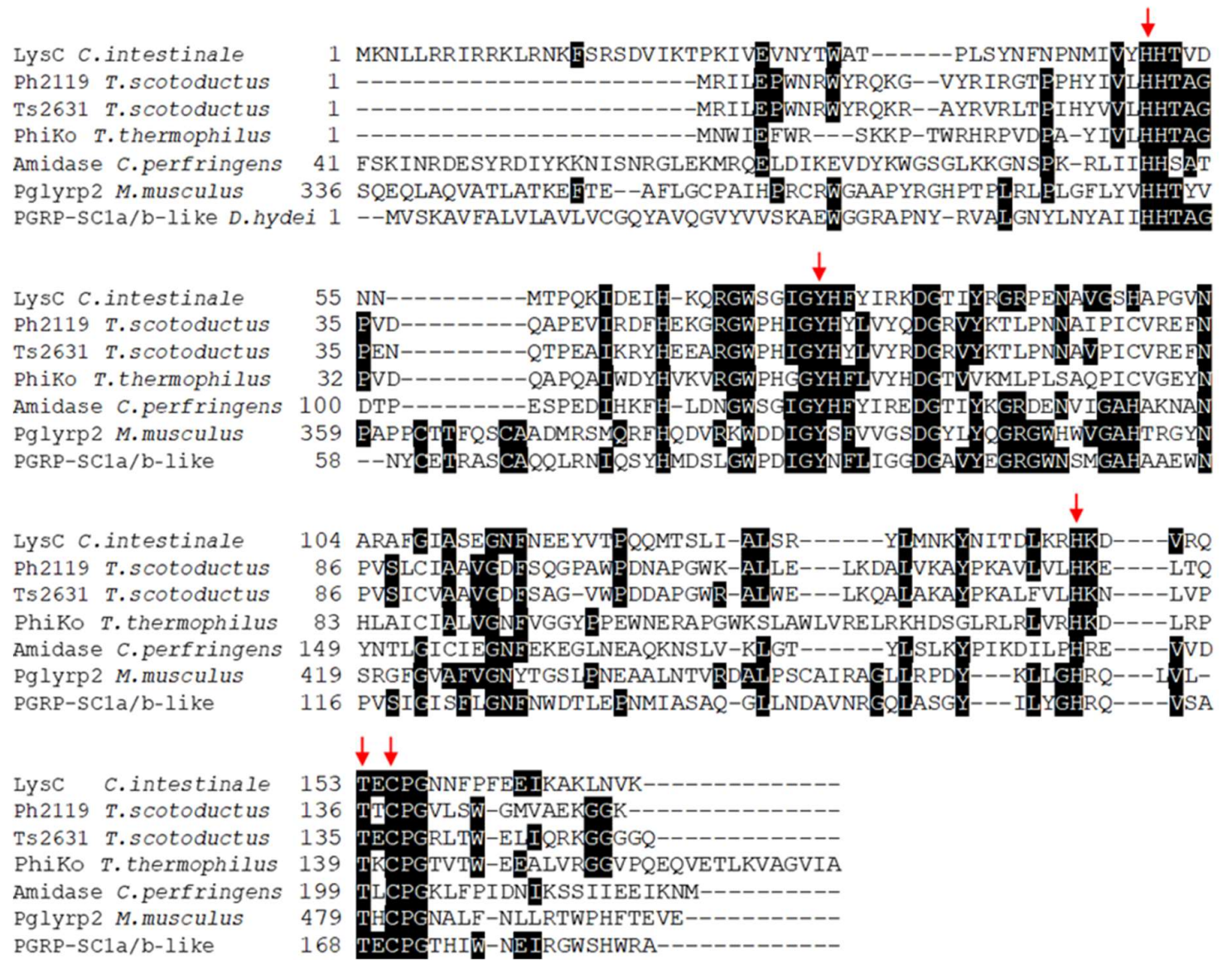

Figure 1. Multiple-sequence alignment of amino acid sequences of LysC lytic enzyme, Ph2119 and Ts2631 endolysins, $N$-acetylmuramoyl-L-alanine amidase from Clostridium perfringens, and eukaryotic peptidoglycan recognition proteins. The alignment was performed using Clustal Omega. Black boxes highlight conserved amino acids. LysC from C. intestinale URNW with conserved residue pattern similar to that of the thermostable Ph2119 endolysin was chosen for further analysis. The red arrows indicate conserved residues His50, Tyr76, His147, Thr153, and Cys155 of LysC, which are indispensable for amidase activity (https://www.ncbi.nlm.nih.gov/protein/ERK30183.1).

To test whether lysC gene, similarly to genes coding for Ph2119 and Ts2631 endolysins, is of phage origin, the contig 00012 of the whole genome sequence (APJA01000012.1) of C. intestinale strain URNW was analyzed by the online tool PHAge Search Tool Enhanced Release (PHASTER) [18]. Only one intact $64.7 \mathrm{~Kb}$ prophage region (coordinates 461851-526605 nt) restricted by two attachment sites attL and attR was identified. Genomic localization of the lys $C$ gene (coordinates 584335-584853 nt), separated by more than $68 \mathrm{~kb}$ from the nearest annotated phage gene, indicates that it probably encodes a bacterial autolysin involved in peptidoglycan remodeling rather than a phage lytic enzyme. The identical gene (610419-610937) is also present in C. intestinale DSM 6191 genome (NZ_FQXU01000003), and similarly, it is not located within any predicted prophage region (data not shown).

\subsection{LysC Characterization and Activity Assays}

Recombinant LysC was overproduced in E. coli and purified to near homogeneity (Figure 2A). The oligomeric state of the protein was investigated by size-exclusion chromatography. As shown in Figure S1, the protein eluted as a single peak at a volume of $13.02 \mathrm{~mL}$, which corresponds to a molecular weight of 23,380. This value is only 1130 higher than that calculated by ProtParam for the recombinant protein $\left(\mathrm{M}_{\mathrm{r}}=22,250\right)$, suggesting that LysC exists in solution in a monomeric form. 
The lytic activity of the protein was determined by zymogram assay (Figure 2B). LysC was able to digest $C$. intestinale cells embedded in the zymogram gel, generating a clearing band (Figure $2 B(1)$ ). Subsequently, the zymogram assay was used to screen the activity of LysC against several Gram-positive bacteria. The lytic band was observed for C. sporogenes DSM 767 (Figure 2B(2)), B. cereus ATCC 13061 (Figure 2B(3)), M. luteus ATCC 4698 (Figure 2B(4)), and S. aureus ATCC 25923 (Figure 2B(5)). No lysis was observed for C. perfringens strain Cp39 (S. M. Swift, personal communication) and B. subtilis 168 DSM 23778 (data not shown). Bovine serum albumin (BSA, $5 \mu \mathrm{g}$ ) served as a negative control in this assay (Figure 2A) and as expected, no clearing zone was observed in the zymogram gel (Figure 2B(1)).
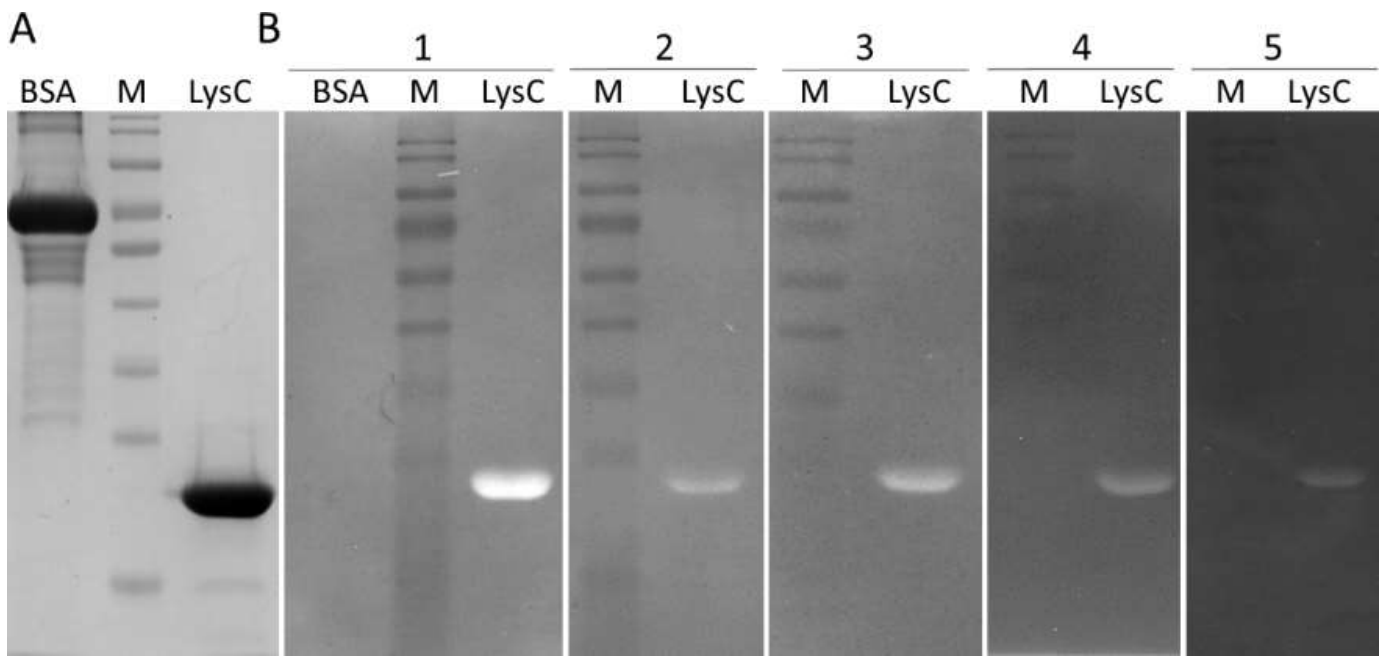

Figure 2. The SDS-PAGE profile and zymogram analysis of the lytic activity of LysC. (A) SDS-PAGE $(12.5 \%)$ of $1 \mu \mathrm{g}$ of bovine serum albumin (BSA) and purified LysC; (B) Zymogram analysis showing lytic activity of LysC against (1) C. intestinale DSM 6191, (2) C. sporogenes DSM 767, (3) B. cereus ATCC 13061, (4) M. luteus ATCC 4698, and (5) S. aureus ATCC 25923; BSA in panel 1 served as a negative control; Lytic activity of LysC is indicated by a single cleared band. M: PageRuler pre-stained protein ladder, 10 to $180 \mathrm{kDa}$ (Thermo Fisher Scientific).

Since the results of the zymograms show the lytic effect of LysC against $S$. aureus, an important human pathogen causing a range of clinical infections [19], the next step was to quantify the anti-bacterial activity of LysC by colony forming unit (CFU) reduction assay. Two strains of S. aureus ATCC 25923 and ATCC 6538P were chosen for this analysis (Figure 3). Spot tests showed total eradication of S. aureus ATCC 25923 cells and the presence of single colonies of $S$. aureus ATCC $6538 \mathrm{P}$ after $1.5 \mathrm{~h}$ incubation with $500 \mu \mathrm{g} / \mathrm{mL}$ of LysC at $37^{\circ} \mathrm{C}$ (Figure $3 \mathrm{~A}, \mathrm{~B}$ ). On average, LysC reduced the cell number of S. aureus ATCC 25923 by more than $5.12 \pm 0.14 \log$ units whereas a reduction of more than $4.15 \pm 1.67$ in cell number was observed for S. aureus ATCC 6538P (Figure 3C). However, bacterial colonies of the latter strain after $24 \mathrm{~h}$ of agar plates incubation at $37^{\circ} \mathrm{C}$ were clearly smaller than that of S. aureus ATCC 25923 (Figure 3B). Moreover, it was difficult to cultivate the S. aureus ATCC 6538P strain in a standardized way, which resulted in lower reproducibility of bactericidal assay results for this strain (Figure 3C). 


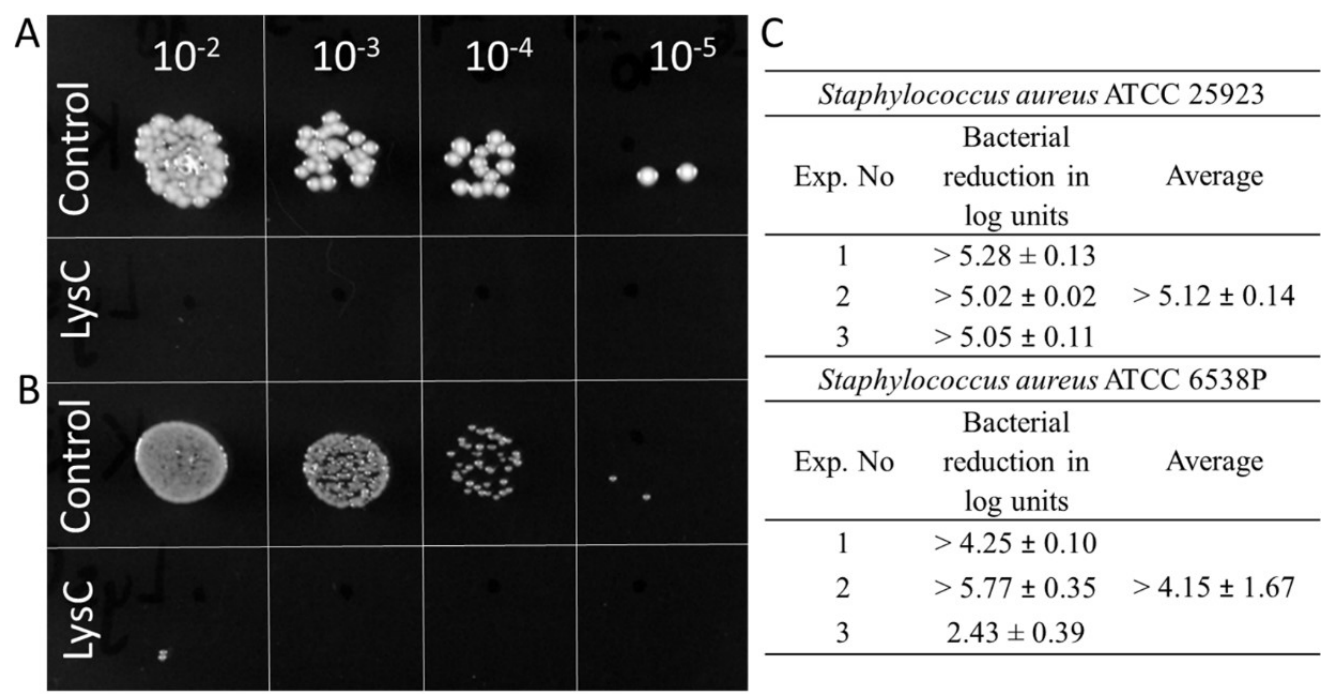

Figure 3. Antimicrobial activity of LysC. (A) Activity against S. aureus ATCC 25923; (B) Activity against S. aureus ATCC 6538P. Both bacteria $\left(>10^{5}\right)$ were mixed with LysC dissolved in 20 mM HEPES buffer, $\mathrm{pH} 7.4$, to a final volume of $300 \mu \mathrm{L}$ and a final enzyme concentration of $500 \mu \mathrm{g} / \mathrm{mL}$. The mixtures were incubated at $37^{\circ} \mathrm{C}$ for $1.5 \mathrm{~h}$. Aliquots of $5 \mu \mathrm{L}$, containing serial 10-fold dilutions prepared in $20 \mathrm{mM}$ HEPES buffer, pH 7.4, were spotted onto tryptic soy broth (TSB) agar plate. The plate was incubated overnight, and then photographed; (C) Serial 10-fold dilutions of controls and reactions with LysC, in a volume of $100 \mu \mathrm{L}$ were spread onto TSB agar plates. After an overnight incubation at $37^{\circ} \mathrm{C}$, colony forming units (CFUs) were counted and the antibacterial activity was reported as bacterial reduction in logarithmic units relative to the untreated control.

\subsection{Evaluation of LysC Activity by An Electron Microscopy}

Transmission electron microscopy studies were performed to visualize the antibacterial activity of LysC against S. aureus ATCC 25923 (Figure 4). In the control samples, round, uniformly shaped bacteria with intact cell walls were clearly visible. Incomplete or completely formed septum was noticed in many of the control cells, indicating that there were in the exponential phase of growth (Figure 4A). Addition of LysC to S. aureus cells led to significant morphological alterations (Figure 4B). One and half hour after incubation, many cells, while maintaining a round shape, lost the cell wall smoothness, and spherical or unstructured components protruding from the cell surface were seen. In addition, no distinction between the cytoplasmic membrane and peptidoglycan could be observed. In many cases, aberrant septum was displayed with attached mesosome-like structures, suggesting abnormal cell division. Finally, in some cells the cytoplasm content leaked out through punctures in the bacterial cell wall, however, we did not observe bacterial ghosts, characteristic for Gram-positive bacteria treated with antibacterial agents [20] (Figure 4B). Unexpectedly, the TEM results showed an increase in cell wall roughness and accumulation of membrane stacks inside LysC-treated cells, but not cell rupture and bacterial shape alterations, as was seen previously in bacteria treated with Ts2631 endolysin [14]. 


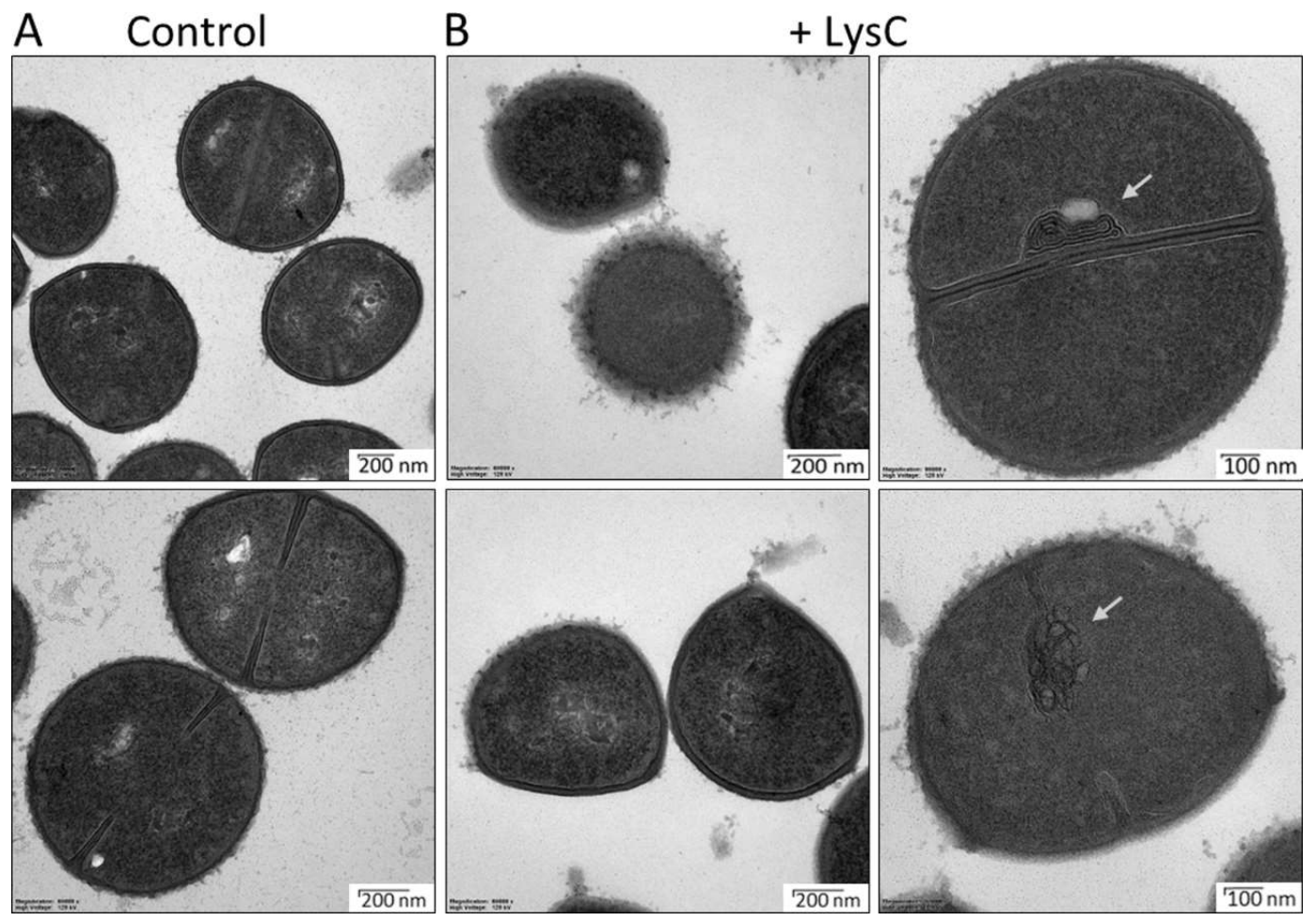

Figure 4. Transmission electron microscopy of Staphylococcus aureus ATCC 25923 cells treated with LysC enzyme. (A) Untreated cells of S. aureus ATCC 25923; (B) S. aureus ATCC 25923 treated with LysC (500 $\mu \mathrm{g} / \mathrm{mL}$ ) for $1.5 \mathrm{~h}$ at $37^{\circ} \mathrm{C}$. The dark and light areas correspond to high and low electron densities of the samples, respectively. Grey arrows show abnormal membranes accumulation, which was characteristic for many cells after incubation with LysC.

\subsection{Crystal Structures of Ph2119 Endolysin and LysC}

As a reference, we used the crystal structure of Ts2631 endolysin previously determined to $1.95 \AA$ resolution (Protein Data Bank (PDB) entry: 6FHG). The peptidoglycan binding site of the Ts2631 protein showed an elongated cleft-like architecture with four residues coordinating a zinc atom located at the bottom of the groove-His30, Tyr58 (mediated by a water molecule), His131, and Cys139 [15]. In the present work, we determined the crystal structures of Ph2119 endolysin and LysC, both to $1.2 \AA$ resolution. Data collection and refinement statistics are summarized in Table 1. The structure of $\mathrm{Ph} 2119$ endolysin was determined by molecular replacement using the coordinates of Drosophila melanogaster PGRP-LC as a search model (PDB entry: 2F2L). The Ph2119 endolysin, in turn, was used as a model in molecular replacement to determine the structure of LysC. The Ph2119 protein structure superimposes well on the Ts2631 endolysin structure with a root-mean-square deviation (RMSD) of $0.36 \AA$ for $111 \mathrm{C} \alpha$ atoms aligned (Figure 5A). In contrast to the Ts2631 enzyme, the $\mathrm{N}$-terminus of $\mathrm{Ph} 2119$ endolysin does not contribute to dimer stabilization but is associated with the core domain through three hydrogen bonds (Trp7'/Lys70", Arg9'/Glu41", and Tyr11'/Glu48"). The Ph2119 endolysin structure displays a mixed fold of a five-stranded $\beta$-sheet ( $\beta 1-\beta 5$ ) flanked by helices $\alpha 2$ and $\alpha 3$, one from each side, yielding a sequence of secondary structure elements $\alpha 1 / \beta 1 / \beta 2 / \alpha 2 / \beta 3 / \beta 4 / \alpha 3 / \beta 5 / \alpha 4$ (Figure $5 \mathrm{~B}$ ). The active site is located in the peptidoglycan binding groove in the center of the molecule and consists of His30, His132, Cys140, and a phosphate ion (Figure 5C). The phosphate group was modeled in two adjacent positions in Ph2119 endolysin as well as in the LysC structure, with occupancies of 0.8 and 0.2. The oxygen of the phosphate group is bound to the $\mathrm{Zn}^{2+}$ atom, occupying the position of the peptidoglycan oxygen, when it binds during the lysis. In this way, the phosphate group may potentially block the binding site of PGs. 

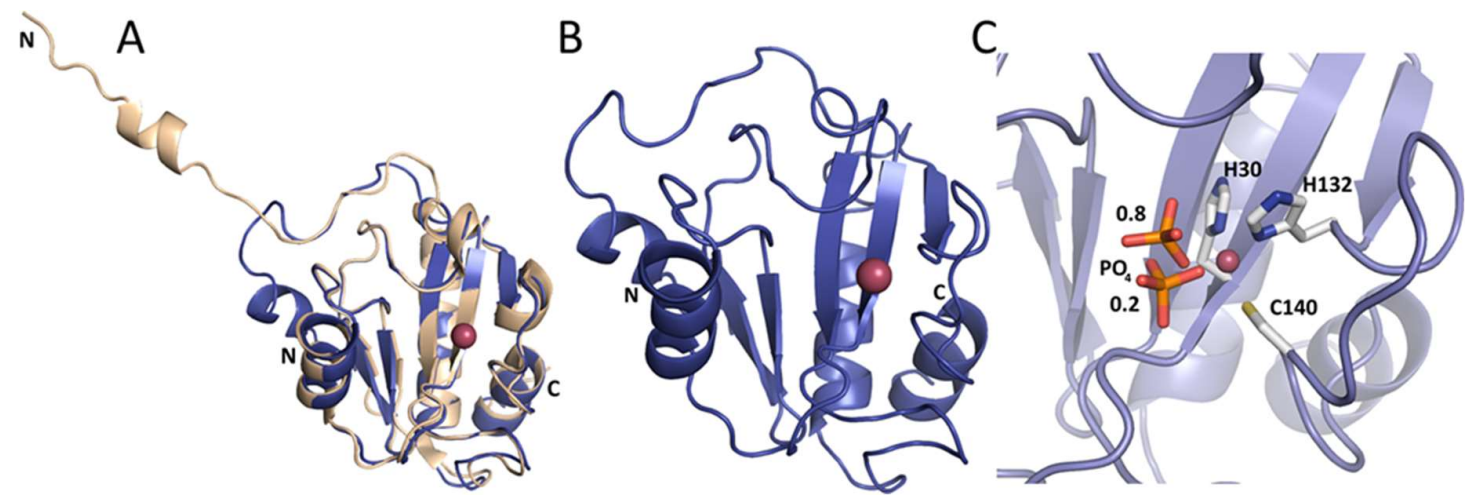

Figure 5. (A) Ts2631 endolysin (beige) superimposed on Ph2119 endolysin (blue). Unlike Ts2631, the N-terminus of Ph2119 folds onto itself and does not contribute to dimer stabilization. (B) Ph2119 endolysin with $\mathrm{Zn}^{2+}$ (pink sphere). (C) Close view of the $\mathrm{Zn}^{2+}$ site with coordinating side chains (H30, H132, and C140) and a phosphate group (in sticks representation) shown in two positions with occupancies of 0.8 and 0.2 , as indicated by the numbers in the figure.

Table 1. Data collection and refinement statistics.

\begin{tabular}{|c|c|c|c|}
\hline \multicolumn{2}{|c|}{ Data Collection } & Ph2119 PDB ID: 6SU5 & LysC PDB ID: 6SSC \\
\hline \multicolumn{2}{|c|}{ Space group } & $\mathrm{P} 2{ }_{1}{ }_{1} 2_{1}$ & $\mathrm{P} 2{ }_{1}{ }_{1} 2_{1}$ \\
\hline \multirow{2}{*}{ Cell Dimensions } & $a, b, c(\AA)$ & $32.0,62.6,74.5$ & $37.4,53.8,76.7$ \\
\hline & $\alpha, \beta, \gamma\left({ }^{\circ}\right)$ & $90,90,90$ & $90,90,90$ \\
\hline \multicolumn{2}{|c|}{ Wavelength $(\AA)$} & 0.97954 & 0.97951 \\
\hline \multicolumn{2}{|c|}{ Resolution $(\AA)$} & $62.6-1.17(1.19-1.17)$ * & $14.90-1.21(1.23-1.21)$ * \\
\hline \multicolumn{2}{|c|}{$R_{\text {merge }}$} & $0.070(0.65)$ & $0.066(1.11)$ \\
\hline \multicolumn{2}{|c|}{ Mean I/ $\sigma(\mathrm{I})$} & $8.1(1.4)$ & $12.1(1.3)$ \\
\hline \multicolumn{2}{|c|}{ Completeness (\%) } & $99.1(94.9)$ & $99.8(99.8)$ \\
\hline \multicolumn{2}{|c|}{ Redundancy } & $4.3(3.7)$ & $5.2(5.2)$ \\
\hline \multicolumn{2}{|c|}{ Refinement $(\AA)$} & $48-1.20$ & $14.9-1.21$ \\
\hline \multicolumn{2}{|c|}{$\mathrm{R}_{\text {work }} / \mathrm{R}_{\text {free }}$} & $0.144 / 0.189$ & $0.121 / 0.161$ \\
\hline \multicolumn{2}{|c|}{ No. of atoms } & 1490 & 1467 \\
\hline \multicolumn{2}{|c|}{ Ligands } & $1 \mathrm{Zn}^{2+}, 1 \mathrm{PO}_{4}, 1$ glycerol & $1 \mathrm{Zn}^{2+}, 1 \mathrm{PO}_{4}, 2$ glycerol \\
\hline \multicolumn{2}{|c|}{ No. of water } & 232 & 231 \\
\hline \multicolumn{2}{|c|}{ RMSD of bonds $(\AA)$} & 0.016 & 0.018 \\
\hline \multicolumn{2}{|c|}{ RMSD of angles $\left({ }^{\circ}\right)$} & 2.0 & 2.2 \\
\hline \multirow{3}{*}{ Ramachandran } & Favored regions (\%) & 96.9 & 97.5 \\
\hline & Allowed regions (\%) & 2.5 & 2.5 \\
\hline & Outliers (\%) & 0.6 & 0.0 \\
\hline
\end{tabular}

* Numbers in brackets refer to the highest resolution shells. RMSD: root-mean-square deviation; PDB: Protein Data Bank.

The overall structures of $\mathrm{Ph} 2119$ endolysin and LysC show conserved catalytic domain architecture, including the $\mathrm{Zn}^{2+}$ coordination site (Figure 6A). The overall RMSD is $0.81 \AA$ A, comparing 85 aligned $\mathrm{C} \alpha$ atoms. Unlike $\mathrm{Ph} 2119$ endolysin, LysC has a large part of the $\mathrm{N}$-terminus not present in the electron density maps (23 amino acids in LysC not visible). Most probably these residues could not be traced due to high mobility-intrinsic disorder (Figure 6B). The catalytic site of LysC is composed of His50, 
His147, and Cys155, a motif also present in Ts2631 and Ph2119 endolysins. Other conserved residues, such as His51, Thr52 (HHT motif), Tyr76 (IGYH motif), and Thr153 (T(X)CPG motif) are close to each other in the potential peptidoglycan binding site and may therefore contribute to the catalytic function (Figure 6C). To verify this hypothesis, the seven residues shown in Figure 6C were chosen for site-directed mutagenesis studies to assess their involvement in LysC catalytic activity.
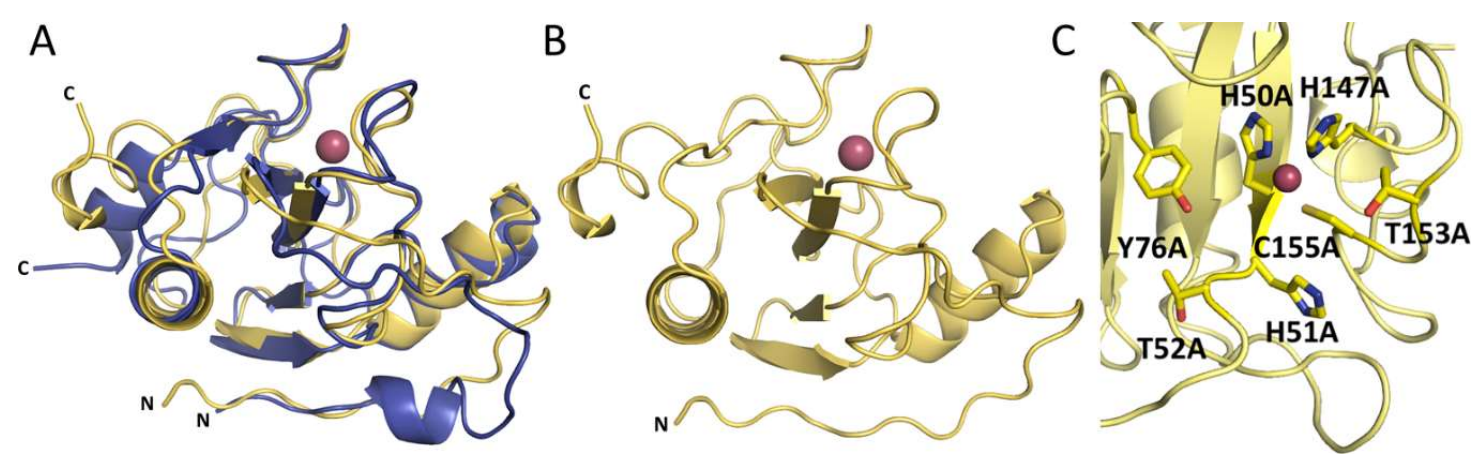

Figure 6. (A) Superposition of LysC (yellow) and Ph2119 endolysin (blue) structures. Except for the flexible $N$-terminal $(N)$ and $C$-terminal $(C)$ regions, the overall structures, including the $\mathrm{Zn}^{2+}$ sites, are conserved. (B) LysC with $\mathrm{Zn}^{2+}$ (pink sphere). (C) The 7 amino acids (sticks representation) around the $\mathrm{Zn}^{2+}$ site, which were substituted by alanine.

\subsection{Antibacterial Activity of LysC Single-Residue Substitution Variants}

Seven residues, His50, His51, Thr52, Tyr76, His147, Thr153, and Cys155, were substituted with alanine, yielding seven different variants of the enzyme (Figure 6C). LysC substitution variants were obtained by site-directed mutagenesis with the use of pET-LysC plasmid with primary lysC gene as a template and mutagenic primers that are listed in Table S1. The sequencing results showed that all recombinant plasmids were successfully constructed. Resulted LysC variants H50A, H51A, T52A, Y76A, H147A, T153A, and C155A (zinc coordinating residues are in bold) were heterologously expressed in E. coli BL21(DE3) and purified to near electrophoretic homogeneity by metal ion affinity chromatography. The antibacterial activity of the LysC variants against S. aureus ATCC 25923 is shown in Table 2. All of them demonstrated anti-S. aureus activity. Three variants of the conserved HHT motif-H50A, H51A, and T52A—caused bacterial reduction of $3.48 \pm 0.30,4.31 \pm 0.19$, and $2.75 \pm 0.11$ $\log$ units that corresponded to as much as $68.0 \%, 84.2 \%$, and $53.7 \%$ of initial LysC activity, respectively. Out of these variants, H50 is directly involved in zinc coordination (Figure 6C). Variants that contain substitution of two other zinc binding residues: H147A and C155A, showed bactericidal activity at the levels of $33.2 \% \pm 0.6$ and $49.8 \% \pm 2.0$, respectively. The variant with the Y76A substitution had antibacterial activity of $80.5 \% \pm 3.1$. The lowest reduction in $S$. aureus cell number $(1.65 \pm 0.06 \mathrm{log}$ units $)$ was observed for the T153A variant, which represented $32.2 \%$ of the wild-type LysC activity. The results were surprising since we expected that all of the LysC substitution variants would significantly or completely lose their bactericidal activity. In general, alanine substitution of residues closer to the $C$-terminal region had a more pronounced effect on LysC activity than replacement of middle and $\mathrm{N}$-terminal residues. Still, the activity of all substitution variants was quite high, bearing in mind the fact that substitutions of His50, His147, and Cys155 may abrogate zinc binding by the protein. Therefore, we were wondering what other features of the LysC protein may be responsible for its antibacterial activity. 
Table 2. Antimicrobial activity of LysC variants. Activities are expressed as bacterial reduction in logarithmic units and as percentage in relation to the native LysC control (average from three replicate measurements \pm standard deviation).

\begin{tabular}{ccc}
\hline Variants & $\begin{array}{c}\text { Bacterial Reduction in log } \\
\text { Units }\end{array}$ & Relative Activity (\%) \\
\hline LysC & $5.12 \pm 0.14$ & $100 \pm 2.7$ \\
H50A & $3.48 \pm 0.30$ & $68.0 \pm 5.9$ \\
H51A & $4.31 \pm 0.19$ & $84.2 \pm 3.7$ \\
T52A & $2.75 \pm 0.11$ & $53.7 \pm 2.1$ \\
Y76A & $4.12 \pm 0.16$ & $80.5 \pm 3.1$ \\
H147A & $1.70 \pm 0.03$ & $33.2 \pm 0.6$ \\
T153A & $1.65 \pm 0.06$ & $32.2 \pm 1.2$ \\
C155A & $2.55 \pm 0.10$ & $49.8 \pm 2.0$ \\
\hline
\end{tabular}

\subsection{In Silico Analysis of the LysC Protein in Search for Motifs Underpinning Antibacterial Activity}

AMPA, a web application for assessing the potential presence of antimicrobial domains in proteins, was used to identify any putative antimicrobial pattern in LysC [21]. Scanning LysC sequence with AMPA predicted, with $1 \%$ of misclassification probability, an antimicrobial region spanning from amino acids $2-19$ of the protein. Therefore, we focused on the evaluation of the antibacterial potential of the $\mathrm{N}$-terminal region of the enzyme. We assumed that the antimicrobial activity of the $\mathrm{N}$-terminal region of LysC may be associated with its high positive charge, which may be responsible for interactions with negatively charged phosphate head groups of bacterial membranes. These types of protein regions with cationic amino acids are often found to adopt a $\alpha$-helical structure [22]. Indeed, in the structure of LysC, lysine and arginine residues are often flanked by hydrophobic amino acids like methionine, isoleucine, leucine, and phenylalanine, and may form an amphipathic $\alpha$-helical structure with antibacterial properties, as shown by helical wheel projection (Figure 7). The in silico analysis using the Antimicrobial Peptide Calculator and Predictor (APD3) supports predictions of the $\alpha$-helical structure formation by the protein fragment comprising both the arginine-rich sequence (residues 1-24) at the $\mathrm{N}$-terminus of $\mathrm{LysC}$ and additional seven residues that include lysine, isoleucine, and two valines (residues 1-31). The helical pattern with a hydrophobic ratio of $33 \%$ and net charge of +9 (Table S2) predicted by APD3 suggests that there may be eight residues on the hydrophobic surface of the $\alpha$-helix and that the putative peptide may interact with bacterial membranes and act as an antimicrobial peptide.

\subsection{Antibacterial Activity of $\mathrm{Lys} C \Delta 2-23$ and a Synthetic Peptide Derived from the N-Terminal Part of the Enzyme}

First, we removed the $N$-terminal extension of LysC (residues 2-23) with 10/23 positively charged residues $(43.5 \%)$, creating a deletion variant of the enzyme, termed LysC $\Delta 2-23$. The zymogram assay showed that the LysC $\Delta 2-23$ retained less than $10 \%$ of wild-type protein activity as judged by densitometric analysis (data not shown). Next, as shown by the spot dilution assay, the addition of purified LysC $\Delta 2-23$ to bacterial cell suspensions, in comparison to the control to which LysC was added, did not cause any noticeable reduction in the number of viable cells (Figure 8A,B). The addition of $500 \mu \mathrm{g} / \mathrm{mL}$ LysC $\Delta 2-23$ reduced the viable cell number of $S$. aureus ATCC 25923 by only $0.5 \pm 0.18$ $\log$ units that stand for over a 10-fold decrease of antibacterial activity of the truncated variant (Figure 8D). Subsequently, based on the LysC amino acid sequence and results of analysis of the APD3 software, we synthesized a 30 amino acid peptide (amino acids 2-31, with 11 positively charged and 10 hydrophobic residues) derived from the $\mathrm{N}$-terminal region of LysC to study its antibacterial potential. The peptide, which we termed Intestinalin, caused pronounced reduction of $5.09 \pm 0.04$ $\log$ units of viable $S$. aureus cell counts in the CFU reduction assay, a level comparable to the activity of wild-type LysC (Figure 8C,D). In addition, a much lower concentration of the peptide $(20 \mu \mathrm{g} / \mathrm{mL}$; $5 \mu \mathrm{M})$ was required to achieve bactericidal activity similar to that achieved by $500 \mu \mathrm{g} / \mathrm{mL}(21.4 \mu \mathrm{M})$ 
of $\mathrm{LysC}$. The $\mathrm{IC}_{50}$ value for the peptide was determined to be $6 \mu \mathrm{g} / \mathrm{mL}(1.5 \mu \mathrm{M})$. These experiments clearly confirm that the $\mathrm{N}$-terminal extension of $\mathrm{LysC}$ is involved in the antibacterial activity. However, bearing in mind the in silico results (Figure 7 and Table S2) we also wanted to verify the conformation of Intestinalin in the presence of bacterial membrane substitutes.

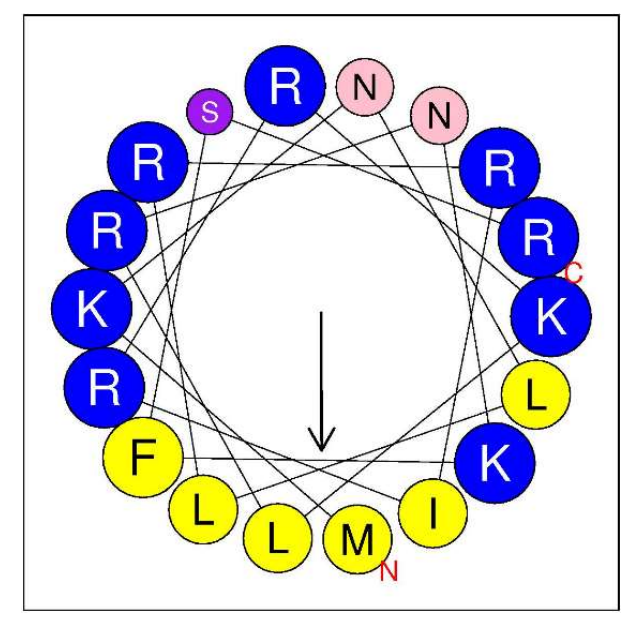

Figure 7. Helical wheel diagram of the $N$-terminal region of LysC. The projection was obtained from HeliQuest (http://heliquest.ipmc.cnrs.fr/cgi-bin/ComputParams.py). Predicted hydrophobic face includes I, M, L, L, and F. Positively charged residues are highlighted by blue color, while hydrophobic residues are marked in yellow. Polar uncharged residues are represented by purple (S) and pink (N). Size of the analysis window was 18 amino acids. The arrow represents the helical hydrophobic momentum.

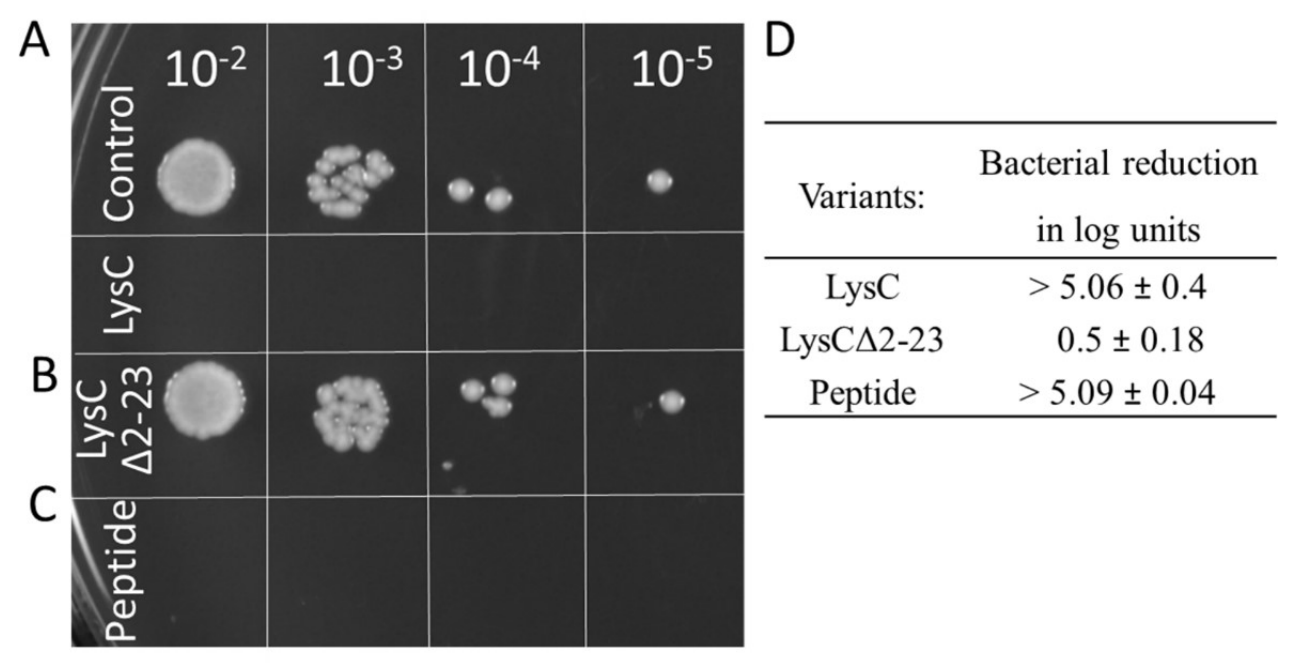

Figure 8. Antimicrobial activity of LysC $\Delta 2-23$ and the Intestinalin peptide against S. aureus ATCC 25923. Antibacterial test with LysC served as a positive control. Drops in a volume of $5 \mu \mathrm{L}$, containing serial 10-fold dilutions of (A) control samples and samples with LysC, (B) LysC $\Delta 2-23$ and (C) 30 aa peptides (Intestinalin), respectively, were spotted onto TSB agar. Plates were incubated overnight, and then photographed; (D) Antibacterial activities are expressed as bacterial reduction in logarithmic units relative to the untreated control (average from three replicate measurements \pm standard deviation).

\subsection{Secondary Structure of Intestinalin}

Many $\alpha$-helical antibacterial peptides are unstructured in solution, but in the presence of membranes they adopt amphipathic helical structures [23]. To test this hypothesis, we used circular 
dichroism spectroscopy and investigated the secondary structure of the peptide without and in the presence of detergents that mimic bacterial membranes. The results show that the peptide, alone or in the presence of lauryl- $\beta$-D-maltoside (DDM) and lauryldimethylamine $N$-oxide (LDAO) is unstructured in solution. However, in the presence of sodium dodecyl sulfate (SDS) and n-dodecylphosphocholine (DPC) the peptide adopts $\alpha$-helical conformation (Figure 9).

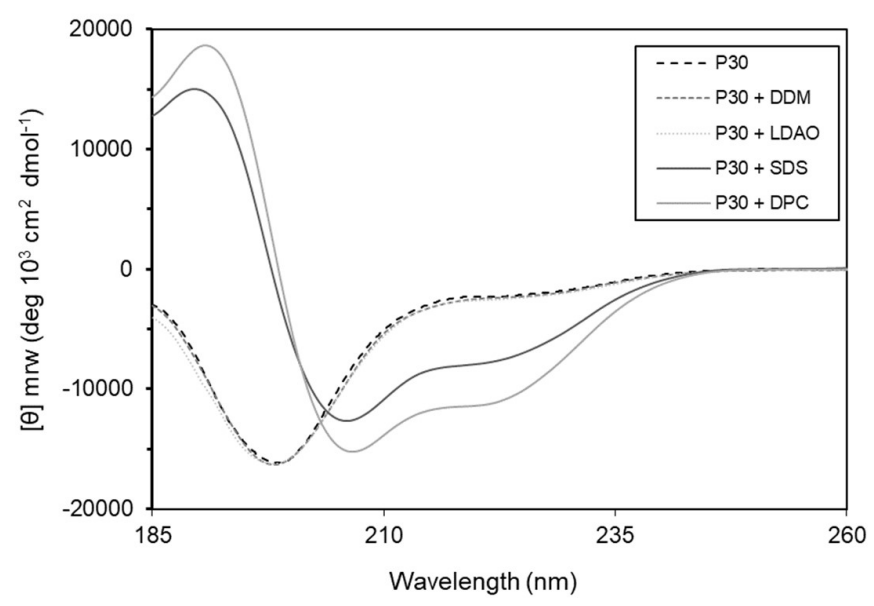

Figure 9. Circular dichroism spectra of P30 peptide show $\alpha$-helical conformation of Intestinalin (P30) in the presence of detergents SDS and DPC (solid lines). Without addition of detergents or in the presence of DDM or LDAO (dotted lines) Intestinalin is in a randomly coiled state; DDM: lauryl- $\beta$-D-maltoside; DPC: $n$-dodecylphosphocholine; SDS: sodium dodecyl sulfate; LDAO: lauryldimethylamine $N$-oxide.

\section{Discussion}

The application of partially purified phage-associated endolysin to exogenously lyse the cell wall of groups A and C of hemolytic streptococci was first reported in 1958 [24]. Since then, many endolysins have been characterized and applied as antibacterial agents as an alternative to conventional antibiotics [25]. However, the success of antibacterial application of endolysins and antibacterial agents would not be possible without a comprehensive understanding of their biochemical, biophysical, and antibacterial properties $[19,26,27]$. The two endolysins under study in our laboratory, Ts2631 and Ph2119, which originate from T. scotoductus bacteriophages, reveal structural features characteristic for type 2 amidases (family: PF01510), with a $\mathrm{Zn}^{2+}$ ion coordinated by two histidines and a cysteine residue. Both these proteins show amino acid sequence and structure similarity to numerous enzymes from mesophilic bacteria, including the LysC lytic enzyme of $C$. intestinale URNW (Figure 1). LysC, as indicated by in silico analysis of its encoding gene and flanking DNA fragment, is not a phage protein, but probably represents an example of bacterial autolysins of the family of type 2 amidases (http://pfam.xfam.org/family/PF01510). It is less likely that LysC functions as a bacteriocin, because, as determined by SignalP software [28], the enzyme lacks a recognizable signal peptide that may facilitate its secretion. The other possibility is that the $l_{y s} C$ gene is reminiscent of temperate phage infection, where most of the prophage sequences were lost over time and the protein adopted the role of a bacterial autolysin.

Well characterized examples of autolysins with type 2 amidase activity include AtlE from S. epidermidis with an amidase domain AmiE [29,30], and AmpD from Citrobacter freundii [17]. Both, AmiE (PDB entry: 3LAT) and AmpD (PDB entry: 2Y28) adopt a globular fold, with several $\alpha$-helices surrounding the central $\beta$-sheet that makes them similar to LysC. These enzymes are also zinc-dependent amidases, coordinating a zinc atom by a His/His/Asp triad, although, in the amino acid sequence of LysC a cysteine residue replaces the aspartate $[17,30]$. However, even though these three proteins share the same fold, they also exhibit significant differences. AmiE is a part of the main S. epidermidis Autolysin E, AtlE [29], which is a modular protein comprised of a signal peptide, a pro-peptide, an amidase domain 
(AmiE), and a glucosaminidase domain linked to AmiE by three repeats (R1-R3) [29]. The second amidase, AmpD, is an enzyme which takes part in the cell-wall recycling pathway and as such has a strict specificity for 1,6-anhydro-muropeptides and does not recognize intact peptidoglycan [31]. Similarly to research on $\mathrm{AmpD}$, we aim to reveal the substrate specificity of LysC and the regulatory mechanism of its potential amidase activity either by performing in silico docking studies or peptidoglycan digestion assays [30]. It is also possible, that having the pI of 9.96 and a highly positively charged $\mathrm{N}$-terminal region, LysC destabilizes bacterial membranes by electrostatic interactions. This scenario was postulated for recently discovered TSPphg lysin [32].

The main objective of the present study was to characterize the newly discovered lytic enzyme, similar to Ts2631 endolysin in the context of its putative antimicrobial potential [14]. This goal was achieved by successful application of LysC against the high priority pathogen S. aureus (Figures 3 and 4). So far, only few endolysin-like amidases have been tested as antibacterial agents. The best known example is the major pneumococcal autolysin LytA, which has been found to be active against a $\beta$-lactam-resistant $S$. pneumoniae in mice peritonitis-sepsis models [33]. LysC is active against Clostridium species, specifically C. intestinale and C. sporogenes, as well as B. cereus, M. luteus, and S. aureus (Figure 2). We revealed its anti-staphylococcal potential, which shows on average the $5.12 \pm 0.14$ bacterial $\log$ reduction after $1.5 \mathrm{~h}$ incubation with S. aureus cells at $37^{\circ} \mathrm{C}$ (Figure 3C). However, the antibacterial application of other autolysins against $S$. aureus was moderately successful [34]. For example, LytM autolysin that cleaves pentaglycine crossbridges of $S$. aureus peptidoglycan was not efficient in combating S. aureus in mice models of chronic S. aureus infected eczema [34]. In addition, recombinantly produced S. aureus autolysin LytN showed low lytic activity when applied exogenously [35]. A more successful strategy included the use of molecular engineering techniques to fuse the cell wall binding domains (CBDs) to existing autolysins to increase their affinity to bacterial cell walls, thus enhancing their lytic activity [36]. Similar molecular engineering techniques were also applied in case of phage endolysins in order to improve their antibacterial potential $[13,25,37,38]$. For example, exchanging the CBD of Ply187 endolysin from S. aureus phage 187 with the CBD from staphylococcal phage K endolysin, LysK, improved bacteriolytic activity of the chimeric enzyme 10-fold over the parental enzyme, particularly against methicillin-resistant S. aureus strains [39]. Not only CBDs, but also Artilysins, were exchanged between lytic enzymes to enhance their antibacterial activity. Briers and colleagues coined the term Artilysins to describe a group of endolysin-based enzymes designed to penetrate the outer membrane of Gram-negative bacteria and to strengthen the interactions of lytic enzymes with the polyanionic cell surface of Gram-positive bacteria $[12,13]$. Several Artilysins were constructed by fusing endolysins with different outer membrane-destabilizing peptides such as polycationic nonapeptide (PCNP), hydrophobic pentapeptide (HPP) or $\alpha$-helical cathelicidin (SMAP-29) [12,40]. The most efficient in increasing the antibacterial activity was the fusion of the $\mathrm{N}$-terminus of endolysins with designed polycationic peptide (PCNP) [12].

In the present study we showed that LysC antibacterial activity is mediated by its highly cationic $N$-terminal region, as the LysC truncated variant, LysC $\Delta 2-23$, was inactive against S. aureus ATCC 25923 (Figure 8). Moreover, a synthetic peptide derived from the $\mathrm{N}$-terminal region of LysC (Intestinalin) showed anti-staphylococcal activity at the level comparable to the wild-type enzyme (Figure 8). We also checked the antibacterial activity of Intestinalin using four models of the antimicrobial peptide prediction tool, known as the Collection of Anti-Microbial Peptides (CAMP). As seen in Table S3, all four tested models of the prediction tool classified the $\mathrm{N}$-terminal region of LysC as an antimicrobial peptide (AMP) with high probability.

We show that in the presence of detergents that mimic bacterial membranes, Intestinalin adopts in silico analysis, $\alpha$-helical structure, as predicted by HeliQuest, that is characteristic of polycationic antimicrobial peptides [23]. Like most of the $\alpha$-helical peptides, LysC remains unstructured in aqueous solution $[23,41]$, which is consistent with the circular dichroism spectroscopy data presented in Figure 9. Interestingly, the results of our crystallographic studies also show that the $\mathrm{N}$-terminal region of LysC is an intrinsically disordered protein region (IDPR) (Figure 6). It is known that many IDPRs bind 
to artificial and natural membranes and this interaction has been shown to be accompanied by a dramatic increase in their $\alpha$-helical content [42]. This is also in agreement with our results. We strongly believe that LysC may serve as a natural source of a polycationic amino acid sequence with a strong antibacterial activity. Recently, a novel DNA assembly method (VersaTile platform) was developed to create a practically unlimited number of shuffled lytic enzymes variants [38]. Fusion of the Intestinalin to other known or yet-to-be discovered lytic enzymes will open up new possibilities to increase their antibacterial potential and broaden the spectrum of their application.

\section{Materials and Methods}

\subsection{Bacterial Strains, Plasmids, and Culture Conditions}

Escherichia coli DH5 $\alpha$ and E. coli BL21(DE3) strains were used for cloning and recombinant proteins production, respectively. The pET15b expression plasmid used for cloning of the lys $C$ gene was purchased from Merck, Darmstadt, Germany. E. coli, B. cereus ATCC 13061, B. subtilis 168 DSM 23778, and M. luteus ATCC 4698 were grown aerobically in Luria-Bertani (LB) broth at $37^{\circ} \mathrm{C}$. S. aureus ATCC 25923 and S. aureus ATCC 6538P were grown in tryptic soy broth (TSB) (Graso Biotech, Starogard Gdanski, Poland). When necessary, LB was supplemented with $100 \mu \mathrm{g} / \mathrm{mL}$ of ampicillin. C. intestinale DSM 6191 and C. sporogenes DSM 767 were grown anaerobically in TSB at $37^{\circ} \mathrm{C}$ without shaking.

\subsection{DNA Manipulations}

Standard protocols for molecular cloning, polymerase chain reaction (PCR), DNA analysis, and bacterial transformation were applied [43]. The ${ }_{y s} C$ gene coding for LysC lytic enzyme was synthesized by GeneArt Gene Synthesis Service (Life Technologies, Regensburg, Germany) and amplified by PCR with use of primers listed in Table S1, specifically lysC-nde-f and lysC-bam-h-r. The PCR product was digested with NdeI and BamHI enzymes and cloned into the corresponding sites of pET-15b vector to generate pET-LysC. Primer LysC $\Delta 2-23$ instead of lysC-nde-f was used to generate by PCR and to clone into $\mathrm{pET15b}$, a truncated version of $l y s C$ gene yielding plasmid pET-LysC $\Delta 2-23$. This resulted in the introduction of a His-tag moiety to $N$-terminus of each recombinant enzyme. Mutations in seven codons of $l y s C$ gene were independently introduced by PCR according to the instruction manual of the QuikChange II Site-Directed Mutagenesis kit (Agilent Technologies, Santa Clara, CA, USA). The mutagenic oligonucleotides are shown in Table S1. PCRs for single codon mutations were run with the use of pET-LysC as a template. The resulting mutant variants were verified by DNA sequencing. Plasmids constructed in this study were deposited in the Collection of Plasmids and Microorganisms, KPD, University of Gdansk, Gdansk, Poland.

\subsection{Overproduction and Purification of Recombinant Proteins}

The overnight cultures of E. coli BL21(DE3) strain harboring the recombinant plasmids (pET-LysC and pET-LysC $\triangle 2-23$ ) constructed as described above or pET-15b vector harboring ph2119 gene, termed pMP20 [9], were diluted 100-fold in $1 \mathrm{~L}$ of fresh LB broth and grown to $\mathrm{OD}_{600}=0.5$. Then, protein overproduction was induced with isopropyl- $\beta$-d-thiogalactopyranoside (IPTG) brought to $1 \mathrm{mM}$ and carried out for $4 \mathrm{~h}$ at $37{ }^{\circ} \mathrm{C}$. Cells were harvested, suspended in $30 \mathrm{~mL}$ of NPI-10 buffer $(50 \mathrm{mM}$ $\mathrm{NaH}_{2} \mathrm{PO}_{4}, \mathrm{pH} 8.0,300 \mathrm{mM} \mathrm{NaCl}, 10 \mathrm{mM}$ imidazole, $0.1 \%$ Triton X-100, $10 \%(v / v)$ glycerol) and disrupted by sonication on ice ( 30 bursts of $10 \mathrm{~s}$ at an amplitude of $12 \mu \mathrm{m}$ ). The cell lysates were centrifuged at $11,000 \times g$ for $20 \mathrm{~min}$ at $4{ }^{\circ} \mathrm{C}$. Supernatants with His-tagged recombinant proteins were applied to a cobalt-based immobilized Metal Affinity Chromatography (IMAC) with $1 \mathrm{~mL}$ HiTrap TALON crude columns (GE Healthcare), washed with NPI buffer containing $20 \mathrm{mM}$ imidazole and eluted with the NPI buffer without $0.1 \%$ Triton X-100, containing $150 \mathrm{mM}$ imidazole. LysC purity was further analyzed by size exclusion chromatography (SEC) on a Superdex 75 10/300 GL column (GE Healthcare, Chicago, IL, USA) equilibrated with buffer A (50 mM NaH $\mathrm{PO}_{4}, 300 \mathrm{mM} \mathrm{NaCl}, \mathrm{pH}$ 8.0). Sodium dodecyl sulfate-polyacrylamide gel electrophoresis (SDS-PAGE) was used to assess protein 
homogeneity. Fractions containing pure proteins were dialyzed against $20 \mathrm{mM} \mathrm{MES,} \mathrm{pH} 6.0$ for crystallography studies or against 20 mM HEPES, pH 7.4 for activity testing. Protein concentration was determined using the Bradford assay [44].

\subsection{Bioinformatics Analysis}

Protein sequences were aligned with CLUSTAL Omega (software available at http://www.clustal. org/omega/) [45]. PHASTER was utilized for the identification of prophage sequences within the genome of C. intestinale URNW [18]. The AMPA web software (http://tcoffee.crg.cat/apps/ampa) was applied in a search for LysC regions with antibacterial potential. The antibacterial properties of the $N$-terminal extension of LysC and physicochemical properties of the 30 aa peptide (Intestinalin), including amino acid composition, molecular weight, hydrophobic ratio, net charge, and protein-binding potential were predicted with the use of Antimicrobial Peptide Calculator and Predictor (APD3) (http: //aps.unmc.edu/AP/prediction/prediction_main.php) [46]. Helical wheel projection of the 18 amino acid $N$-terminal regions of LysC was generated using HeliQuest [47]. The antimicrobial activity of the synthetic peptide Intestinalin was predicted by the Collection of Anti-Microbial Peptides (CAMP) (available at http://www.camp.bicnirrh.res.in/predict/) [48]. This tool is based on four different algorithms: support vector machine (SVM), random forest (RF), artificial neural network (ANN), and discriminant analysis (DA). As a result, three of these models, namely, SVM, RF, and DA gave a probability score between 0 and 1 , where values above 0.5 mean that the peptide is antimicrobial (AMP) and such information is automatically shown in the results window. The ANN model predicts peptides to be antimicrobial or not antimicrobial (AMP or NAMP).

\subsection{Crystallization, Data Collection, and Structure Determination}

Ph2119 endolysin crystals were grown at $4{ }^{\circ} \mathrm{C}$ from a solution of $8 \mathrm{mg} / \mathrm{mL}$ Ph2119 in $20 \mathrm{mM}$ MES, pH 6.0. Crystals for data collection were obtained using seeding from crystals grown at similar conditions $\left(20 \mathrm{mM} \mathrm{NaKHPO}_{4}\right.$ and 16\% (w/v) polyethylene glycol 3350) in sitting drops in MRC 3-well plates with $200 \mathrm{~nL}$ of protein, $50 \mathrm{~nL}$ seed, and $150 \mathrm{~nL}$ reservoir solution $(30 \mathrm{mM} \mathrm{NaKHPO} 4$ and $16 \%$ $(w / v)$ PEG 3350). LysC crystals were grown in a similar way at $20{ }^{\circ} \mathrm{C}$ from $200 \mathrm{~nL} 8.8 \mathrm{mg} / \mathrm{mL} \mathrm{LysC}$ protein in $10 \mathrm{mM}$ HEPES, pH 7.4 mixed with $200 \mathrm{~nL}$ reservoir $\left(10 \mathrm{mM} \mathrm{NaKHPO}_{4}\right.$ and 22\% (w/v) PEG 3350). For data collection the crystals were transferred to cryo-solutions containing the reservoir and protein buffers solutions supplemented with $25 \%(v / v)$ glycerol, and flash-frozen in liquid nitrogen. Data to $1.2 \AA$ were collected at Diamond Light Source beamLine i04. The data were processed using the automatic script xia2-3dii [49] with the XDS package [50] and AimLess [51]. The structure of Ph2119 endolysin was determined using automated molecular replacement method with the MrBUMP software package [52]. The peptidoglycan recognition protein from Drosophila melanogaster with PDB entry: 2F2L was found to be a successful template structure. The Ph2119 structure was refined using Refmac5 [53] for convergence and model building was done using Coot graphics software [54]. The final model includes amino acids $16-169$, one $\mathrm{Zn}^{2+}$ atom, one phosphate group, and one glycerol molecule. The structure of LysC was determined using molecular replacement with MrBUMP software and Ph2119 as a template. The structure was refined and built similarly to Ph2119, and the final model contained amino acids 44-192, one $\mathrm{Zn}^{2+}$ atom, two phosphate groups, and two glycerol molecules.

\subsection{Protein Sequences Accession Numbers}

The structures were deposited with the Protein Data Bank with PDB codes: 6SU5 and 6SSC for the Ph2119 and LysC structures, respectively. The GenBank accession numbers for the protein sequences of the LysC lytic enzyme, Ph2119 endolysin, Ts2631 endolysin, PhiKo lysozyme, Clostridium perfringens N-acetylmuramoyl-L-alanine amidase, Mus musculus Pglyrp2, and Drosophila hydei PGRP-SC1a/b-like are ERK30183.1, AHF20915.1, AIM47292.1, AYJ74695.1, PWX13837.1, AAH19396.1, and XP_023167292.1, respectively. 


\subsection{Zymogram Assay}

Zymogram analysis was performed by using $12.5 \%$ SDS-PAGE containing $0.2 \%(w / v)$ Gram-positive bacterial substrates in a separating gel. After electrophoresis, the gel was gently shaken at $37^{\circ} \mathrm{C}$ for $16 \mathrm{~h}$ in $50 \mathrm{~mL}$ of $25 \mathrm{mM}$ potassium phosphate buffer, $\mathrm{pH} 8.0$ containing 1\% Triton X-100 to allow renaturation of LysC. A clear band resulting from lytic activity was visualized after staining with $1 \%$ $(w / v)$ methylene blue in $0.01 \%(w / v) \mathrm{KOH}$ and subsequent destining with distilled water. Bovine serum albumin (Sigma-Aldrich, St. Louis, MO, USA) served as a negative control. The 12.5\% SDS-PAGE without bacterial cells was run simultaneously and stained with Coomassie Brilliant Blue (Bio-Rad, Hercules, CA, USA).

\subsection{Peptide Synthesis}

The peptide, which we named Intestinalin, was synthesized on a solid phase using a Liberty Blue microwave synthesizer (CEM Inc.). Tenta Gel R RAM resin of $0.19 \mathrm{mmol} / \mathrm{g}$ substitution (Rapp Polymere) was used as a solid support. The synthesis procedure consisted of repeatedly alternating deprotection and coupling steps, according to the manufacturer's protocols (Liberty Blue ${ }^{\mathrm{TM}}$ User Guide). Deprotection was executed with $20 \%$ piperidine. Subsequent acylation of the free amine group with a protected amino acid residue was carried out using diisopropylcarbodiimide/Oxyma activation method. A mixture consisting of $88 \%$ trifluoroacetic acid, $2 \%$ triisopropylsilane, $5 \%$ water and $5 \%$ thioanisole was used for the cleavage of the peptide from the resin and side chains deprotection. The product was precipitated with cold diethyl ether and washed three times with the same solvent. Next, the peptide was dissolved in water and lyophilized. The identity of the peptide was confirmed by mass spectra recorded with a Biflex MALDI TOF spectrometer (Bruker). Purification of the peptide was carried out by a semi-preparative reverse phase high-performance liquid chromatography (RP-HPLC) using a Jupiter Proteo C12 column $(21.2 \times 250$ mm, $4 \mu \mathrm{m}, 90 \AA$ A; Phenomenex). Chromatographic analyses of the crude and pure peptide were performed on an RP-HPLC Varian Pro Star 240 using a Kromasil C8 column $(4.6 \times 250 \mathrm{~nm}, 5 \mu \mathrm{m}, 100 \AA)$.

\subsection{Antimicrobial Activity in Vitro}

S. aureus ATCC 25923 and S. aureus ATCC 6538P cells were grown in TSB at $37^{\circ} \mathrm{C}$ to exponential phase $\left(\mathrm{OD}_{600} \sim 0.45-0.5\right)$. Bacteria were harvested at $4000 \times \mathrm{g}$ for $15 \mathrm{~min}$ at $20^{\circ} \mathrm{C}$, washed with $20 \mathrm{mM}$ HEPES, pH 7.4 and resuspended in the same buffer. For the antimicrobial activity assay, LysC $\Delta 2-23$, LysC or its substitution variants were added at a final concentration of $500 \mu \mathrm{g} / \mathrm{mL}$ to approximately $10^{6}$ of bacterial cells (10-fold dilution) in 20 mM HEPES, pH 7.4 in a final volume of $300 \mu \mathrm{L}$. In case of Intestinalin the final concentration of the peptide was $20 \mu \mathrm{g} / \mathrm{mL}$. To the negative control, the equivalent volume of $20 \mathrm{mM}$ HEPES, pH 7.4 was added instead of LysC enzyme or its derivatives. After $1.5 \mathrm{~h}$ of incubation at $37^{\circ} \mathrm{C}$, reaction mixtures were serially diluted in 20 mM HEPES, pH 7.4 and plated. Simultaneously, $5 \mu \mathrm{L}$ drops were plated onto TSB agar plates to perform spot dilution assays. Colony forming units (CFUs) were counted after overnight incubation at $37^{\circ} \mathrm{C}$. The antibacterial activity was presented in logarithmic units $=\log _{10}(\mathrm{~N} 0 / \mathrm{Ni})$, where $N 0=$ the number of untreated cells (in the negative control) and $\mathrm{Ni}=$ number of treated cells counted after incubation. All experiments were performed in triplicate.

\subsection{Transmission Electron Microscopy}

LysC at a final concentration of $500 \mu \mathrm{g} / \mathrm{mL}$ was mixed with $10^{8}$ of $S$. aureus ATCC 25923 cells in a volume of $500 \mu \mathrm{L}$ of $20 \mathrm{mM}$ HEPES, pH 7.4. In the control reaction, equivalent volume of $20 \mathrm{mM}$ HEPES, $\mathrm{pH} 7.4$ was added to the bacterial cell suspension instead of the enzyme. Samples were incubated for $1.5 \mathrm{~h}$ at $37^{\circ} \mathrm{C}$, washed in phosphate buffer saline (PBS) (Sigma-Aldrich) and fixed overnight at $4{ }^{\circ} \mathrm{C}$ in $2.5 \%$ glutaraldehyde in PBS. Following rinsing, samples were post-fixed in $1 \% \mathrm{OsO}_{4}$ for $1 \mathrm{~h}$ at room temperature. After dehydration in a graded series of ethanol, probes were embedded in EPON resin, 
cut on an ultramicrotome Leica UC7, counterstained with uranyl acetate and lead citrate, and viewed with a FEI Tecnai BioTwin Spirit microscope (FEI Company, Hillsboro, Oregon, United States).

\subsection{Circular Dichroism Spectroscopy}

The secondary structure of Intestinalin was studied by circular dichroism (CD) spectroscopy. A J-815 spectropolarimeter (Jasco) with a 1-mm path length cell was used to record the spectra of Intestinalin $(40 \mu \mathrm{M})$ at $25^{\circ} \mathrm{C}$ from 185 to $260 \mathrm{~nm}$ at $0.1 \mathrm{~nm}$ intervals. The peptide was dissolved in water or $20 \mathrm{mM}$ micelles of lauryl- $\beta$-D-maltoside (DDM), dodecylphosphocholine (DPC), lauryldimethylamine $\mathrm{N}$-oxide (LDAO), and sodium dodecyl sulfate (SDS). Each spectrum represents the average of six scans. $\mathrm{CD}$ data are shown as the mean residue ellipticity $(\theta)$ in degrees $\cdot \mathrm{cm}^{2} \cdot \mathrm{dmol}^{-1}$.

Supplementary Materials: Figure S1. Size-exclusion chromatography analysis of LysC, Table S1. PCR primers used in this study, Table S2. Physicochemical properties of N-terminal region of LysC and Table S3. Antimicrobial peptide prediction of the N-terminal region of LysC. Supplementary materials can be found at http://www.mdpi. com/1422-0067/21/14/4894/s1.

Author Contributions: M.P., M.H., S.A.-K., A.-K.K., and T.K. contributed conception of the study; M.P., M.S., R.K., and M.H. designed and performed the experiments; M.P., M.H., S.A.-K., B.W., O.W., A.-K.K., and T.K. discussed the results obtained; M.P., M.H., A.-K.K., and T.K. curated the data; M.P. wrote the first draft of the manuscript; M.P., M.H., S.A.-K., A.-K.K., and T.K. contributed to manuscript revision; All authors have read and agreed to the published version of the manuscript.

Funding: Funding was provided by the European Union's Horizon 2020 Research and Innovation Programme Virus-X project: Viral Metagenomics for Innovation Value (grant no. 685778) to T.K. and the National Science Centre (Poland) MINIATURA3 grant: DEC-2019/03/X/NZ1/00394 to M.P.

Acknowledgments: We thank Elzbieta Jankowska for peptide synthesis and Steven M. Swift for testing of LysC activity against $C$. perfringens $\mathrm{Cp} 39$.

Conflicts of Interest: The authors declare that the research was conducted in the absence of any commercial or financial relationships that could be construed as a potential conflict of interest.

\section{References}

1. Misra, G.; Rojas, E.R.; Gopinathan, A.; Huang, K.C. Mechanical consequences of cell-wall turnover in the elongation of a Gram-positive bacterium. Biophys. J. 2013, 104, 2342-2352. [CrossRef]

2. Vollmer, W.; Blanot, D.; de Pedro, M.A. Peptidoglycan structure and architecture. FEMS Microbiol. Rev. 2008, 32, 149-167. [CrossRef]

3. Borysowski, J.; Weber-Dabrowska, B.; Górski, A. Bacteriophage endolysins as a novel class of antibacterial agents. Exp. Biol. Med. (Maywood) 2006, 231, 366-377. [CrossRef]

4. Schmelcher, M.; Donovan, D.M.; Loessner, M.J. Bacteriophage endolysins as novel antimicrobials. Future Microbiol. 2012, 7, 1147-1171. [CrossRef]

5. Fischetti, V.A. Development of Phage Lysins as Novel Therapeutics: A Historical Perspective. Viruses 2018, 10, 310. [CrossRef]

6. Vermassen, A.; Leroy, S.; Talon, R.; Provot, C.; Popowska, M.; Desvaux, M. Cell Wall Hydrolases in Bacteria: Insight on the Diversity of Cell Wall Amidases, Glycosidases and Peptidases toward Peptidoglycan. Front. Microbiol. 2019, 10, 331. [CrossRef]

7. Cheng, X.; Zhang, X.; Pflugrath, J.W.; Studier, F.W. The structure of bacteriophage T7 lysozyme, a zinc amidase and an inhibitor of T7 RNA polymerase. Proc. Natl. Acad. Sci. USA 1994, 91, 4034-4038. [CrossRef] [PubMed]

8. Plotka, M.; Kaczorowska, A.K.; Morzywolek, A.; Makowska, J.; Kozlowski, L.P.; Thorisdottir, A.; Skírnisdottir, S.; Hjörleifsdottir, S.; Fridjonsson, O.H.; Hreggvidsson, G.O.; et al. Biochemical Characterization and Validation of a Catalytic Site of a Highly Thermostable Ts2631 Endolysin from the Thermus scotoductus Phage vB_Tsc2631. PLoS ONE 2015, 10, e0137374. [CrossRef] [PubMed]

9. Plotka, M.; Kaczorowska, A.K.; Stefanska, A.; Morzywolek, A.; Fridjonsson, O.H.; Dunin-Horkawicz, S.; Kozlowski, L.; Hreggvidsson, G.O.; Kristjansson, J.K.; Dabrowski, S.; et al. Novel highly thermostable endolysin from Thermus scotoductus MAT2119 bacteriophage Ph2119 with amino acid sequence similarity to eukaryotic peptidoglycan recognition proteins. Appl. Env. Microbiol. 2014, 80, 886-895. [CrossRef] [PubMed] 
10. Love, M.J.; Bhandari, D.; Dobson, R.C.J.; Billington, C. Potential for Bacteriophage Endolysins to Supplement or Replace Antibiotics in Food Production and Clinical Care. Antibiotics (Basel) 2018, 7, 17. [CrossRef] [PubMed]

11. Oliveira, H.; Thiagarajan, V.; Walmagh, M.; Sillankorva, S.; Lavigne, R.; Neves-Petersen, M.T.; Kluskens, L.D.; Azeredo, J. A thermostable Salmonella phage endolysin, Lys68, with broad bactericidal properties against gram-negative pathogens in presence of weak acids. PLoS ONE 2014, 9, e108376. [CrossRef] [PubMed]

12. Briers, Y.; Walmagh, M.; Van Puyenbroeck, V.; Cornelissen, A.; Cenens, W.; Aertsen, A.; Oliveira, H.; Azeredo, J.; Verween, G.; Pirnay, J.P.; et al. Engineered endolysin-based "Artilysins" to combat multidrug-resistant gram-negative pathogens. MBio 2014, 5, 01379-14. [CrossRef] [PubMed]

13. Rodríguez-Rubio, L.; Chang, W.L.; Gutiérrez, D.; Lavigne, R.; Martínez, B.; Rodríguez, A.; Govers, S.K.; Aertsen, A.; Hirl, C.; Biebl, M.; et al. 'Artilysation' of endolysin $\lambda$ Sa2lys strongly improves its enzymatic and antibacterial activity against streptococci. Sci. Rep. 2016, 6, 35382. [CrossRef] [PubMed]

14. Plotka, M.; Kapusta, M.; Dorawa, S.; Kaczorowska, A.K.; Kaczorowski, T. Ts2631 Endolysin from the Extremophilic Thermus scotoductus Bacteriophage vB_Tsc2631 as an Antimicrobial Agent against Gram-Negative Multidrug-Resistant Bacteria. Viruses 2019, 11, 657. [CrossRef] [PubMed]

15. Plotka, M.; Sancho-Vaello, E.; Dorawa, S.; Kaczorowska, A.K.; Kozlowski, L.P.; Kaczorowski, T.; Zeth, K. Structure and function of the Ts2631 endolysin of Thermus scotoductus phage vB_Tsc2631 with unique N-terminal extension used for peptidoglycan binding. Sci. Rep. 2019, 9, 1261. [CrossRef]

16. Liepinsh, E.; Généreux, C.; Dehareng, D.; Joris, B.; Otting, G. NMR structure of Citrobacter freundii AmpD, comparison with bacteriophage T7 lysozyme and homology with PGRP domains. J. Mol. Biol. 2003, 327, 833-842. [CrossRef]

17. Généreux, C.; Dehareng, D.; Devreese, B.; Van Beeumen, J.; Frère, J.M.; Joris, B. Mutational analysis of the catalytic centre of the Citrobacter freundii AmpD N-acetylmuramyl-L-alanine amidase. Biochem. J. 2004, 377, 111-120. [CrossRef] [PubMed]

18. Arndt, D.; Grant, J.R.; Marcu, A.; Sajed, T.; Pon, A.; Liang, Y.; Wishart, D.S. PHASTER: A better, faster version of the PHAST phage search tool. Nucleic Acids Res. 2016, 44, 16-21. [CrossRef]

19. Kaur, J.; Singh, P.; Sharma, D.; Harjai, K.; Chhibber, S. A potent enzybiotic against methicillin-resistant Staphylococcus aureus. Virus Genes 2020, 56, 480-497. [CrossRef]

20. Anderson, R.C.; Haverkamp, R.G.; Yu, P.L. Investigation of morphological changes to Staphylococcus aureus induced by ovine-derived antimicrobial peptides using TEM and AFM. FEMS Microbiol. Lett. 2004, 240, 105-110. [CrossRef]

21. Torrent, M.; Di Tommaso, P.; Pulido, D.; Nogués, M.V.; Notredame, C.; Boix, E.; Andreu, D. AMPA: An automated web server for prediction of protein antimicrobial regions. Bioinformatics 2012, 28, 130-131. [CrossRef] [PubMed]

22. Vermeer, L.S.; Lan, Y.; Abbate, V.; Ruh, E.; Bui, T.T.; Wilkinson, L.J.; Kanno, T.; Jumagulova, E.; Kozlowska, J.; Patel, J.; et al. Conformational flexibility determines selectivity and antibacterial, antiplasmodial, and anticancer potency of cationic $\alpha$-helical peptides. J. Biol. Chem. 2012, 287, 34120-34133. [CrossRef] [PubMed]

23. Mahlapuu, M.; Håkansson, J.; Ringstad, L.; Björn, C. Antimicrobial Peptides: An Emerging Category of Therapeutic Agents. Front. Cell Infect. Microbiol. 2016, 6, 194. [CrossRef]

24. Krause, R.M. Studies on the bacteriophages of hemolytic streptococci. II. Antigens released from the streptococcal cell wall by a phage-associated lysin. J. Exp. Med. 1958, 108, 803-821. [CrossRef]

25. Roach, D.R.; Donovan, D.M. Antimicrobial bacteriophage-derived proteins and therapeutic applications. Bacteriophage 2015, 5, e1062590. [CrossRef]

26. Love, M.J.; Abeysekera, G.S.; Muscroft-Taylor, A.C.; Billington, C.; Dobson, R.C.J. On the catalytic mechanism of bacteriophage endolysins: Opportunities for engineering. Biochim. Biophys. Acta Proteins Proteom. 2020, 1868, 140302. [CrossRef]

27. Freitag-Pohl, S.; Jasilionis, A.; Håkansson, M.; Svensson, L.A.; Kovačič, R.; Welin, M.; Watzlawick, H.; Wang, L.; Altenbuchner, J.; Płotka, M.; et al. Crystal structures of the Bacillus subtilis prophage lytic cassette proteins XepA and YomS. Acta Crystallogr. D. Struct. Biol. 2019, 75, 1028-1039. [CrossRef]

28. Petersen, T.N.; Brunak, S.; von Heijne, G.; Nielsen, H. SignalP 4.0: Discriminating signal peptides from transmembrane regions. Nat. Methods 2011, 8, 785-786. [CrossRef] 
29. Lützner, N.; Pätzold, B.; Zoll, S.; Stehle, T.; Kalbacher, H. Development of a novel fluorescent substrate for Autolysin E, a bacterial type II amidase. Biochem. Biophys. Res. Commun. 2009, 380, 554-558. [CrossRef]

30. Zoll, S.; Pätzold, B.; Schlag, M.; Götz, F.; Kalbacher, H.; Stehle, T. Structural basis of cell wall cleavage by a staphylococcal autolysin. PLoS Pathog. 2010, 6, e1000807. [CrossRef]

31. Carrasco-López, C.; Rojas-Altuve, A.; Zhang, W.; Hesek, D.; Lee, M.; Barbe, S.; André, I.; Ferrer, P.; Silva-Martin, N.; Castro, G.R.; et al. Crystal structures of bacterial peptidoglycan amidase AmpD and an unprecedented activation mechanism. J. Biol. Chem. 2011, 286, 31714-31722. [CrossRef]

32. Wang, F.; Ji, X.; Li, Q.; Zhang, G.; Peng, J.; Hai, J.; Zhang, Y.; Ci, B.; Li, H.; Xiong, Y.; et al. TSPphg Lysin from the Extremophilic Thermus Bacteriophage TSP4 as a Potential Antimicrobial Agent against Both Gram-Negative and Gram-Positive Pathogenic Bacteria. Viruses 2020, 12, 192. [CrossRef]

33. Rodríguez-Cerrato, V.; García, P.; Huelves, L.; García, E.; Del Prado, G.; Gracia, M.; Ponte, C.; López, R.; Soriano, F. Pneumococcal LytA autolysin, a potent therapeutic agent in experimental peritonitis-sepsis caused by highly beta-lactam-resistant Streptococcus pneumoniae. Antimicrob. Agents Chemother. 2007, 51, 3371-3373. [CrossRef]

34. Sabala, I.; Jonsson, I.M.; Tarkowski, A.; Bochtler, M. Anti-staphylococcal activities of lysostaphin and LytM catalytic domain. BMC Microbiol. 2012, 12, 97. [CrossRef]

35. Frankel, M.B.; Schneewind, O. Determinants of murein hydrolase targeting to cross-wall of Staphylococcus aureus peptidoglycan. J. Biol. Chem. 2012, 287, 10460-10471. [CrossRef]

36. Osipovitch, D.C.; Therrien, S.; Griswold, K.E. Discovery of novel S. aureus autolysins and molecular engineering to enhance bacteriolytic activity. Appl. Microbiol. Biotechnol. 2015, 99, 6315-6326. [CrossRef]

37. Gerstmans, H.; Rodríguez-Rubio, L.; Lavigne, R.; Briers, Y. From endolysins to Artilysin ${ }^{\circledR}$ s: Novel enzyme-based approaches to kill drug-resistant bacteria. Biochem Soc. Trans. 2016, 44, 123-128. [CrossRef]

38. Gerstmans, H.; Grimon, D.; Gutiérrez, D.; Lood, C.; Rodríguez, A.; van Noort, V.; Lammertyn, J.; Lavigne, R.; Briers, Y. A VersaTile-driven platform for rapid hit-to-lead development of engineered lysins. Sci. Adv. 2020, 6, eaaz1136. [CrossRef]

39. Mao, J.; Schmelcher, M.; Harty, W.J.; Foster-Frey, J.; Donovan, D.M. Chimeric Ply187 endolysin kills Staphylococcus aureus more effectively than the parental enzyme. FEMS Microbiol. Lett. 2013, 342, 30-36. [CrossRef]

40. Briers, Y.; Walmagh, M.; Grymonprez, B.; Biebl, M.; Pirnay, J.P.; Defraine, V.; Michiels, J.; Cenens, W.; Aertsen, A.; Miller, S.; et al. Art-175 is a highly efficient antibacterial against multidrug-resistant strains and persisters of Pseudomonas aeruginosa. Antimicrob. Agents Chemother. 2014, 58, 3774-3784. [CrossRef]

41. Kumar, P.; Kizhakkedathu, J.N.; Straus, S.K. Antimicrobial Peptides: Diversity, Mechanism of Action and Strategies to Improve the Activity and Biocompatibility In Vivo. Biomolecules 2018, 8, 4. [CrossRef] [PubMed]

42. Uversky, V.N. Intrinsically disordered proteins and their environment: Effects of strong denaturants, temperature, $\mathrm{pH}$, counter ions, membranes, binding partners, osmolytes, and macromolecular crowding. Protein J. 2009, 28, 305-325. [CrossRef] [PubMed]

43. Sambrook, J.; Russell, D.W. The Condensed Protocols from Molecular Cloning: A Laboratory Manual; Cold Spring Harbor Laboratory Press: Cold Spring Harbor, NY, USA, 2006.

44. Bradford, M.M. A rapid and sensitive method for the quantitation of microgram quantities of protein utilizing the principle of protein-dye binding. Anal. Biochem. 1976, 72, 248-254. [CrossRef]

45. Sievers, F.; Wilm, A.; Dineen, D.; Gibson, T.J.; Karplus, K.; Li, W.; Lopez, R.; McWilliam, H.; Remmert, M.; Söding, J.; et al. Fast, scalable generation of high-quality protein multiple sequence alignments using Clustal Omega. Mol. Syst. Biol. 2011, 7, 539. [CrossRef] [PubMed]

46. Wang, G.; Li, X.; Wang, Z. APD3: The antimicrobial peptide database as a tool for research and education. Nucleic Acids Res. 2016, 44, 1087-1093. [CrossRef]

47. Gautier, R.; Douguet, D.; Antonny, B.; Drin, G. HELIQUEST: A web server to screen sequences with specific alpha-helical properties. Bioinformatics 2008, 24, 2101-2102. [CrossRef]

48. Thomas, S.; Karnik, S.; Barai, R.S.; Jayaraman, V.K.; Idicula-Thomas, S. CAMP: A useful resource for research on antimicrobial peptides. Nucleic Acids Res. 2010, 38, 774-780. [CrossRef]

49. Winter, G. Xia2: An expert system for macromolecular crystallography data reduction. J. Appl. Crystallogr. 2010, 43, 186-190. [CrossRef]

50. Kabsch, W. XDS. Acta Cryst. D. Biol. Cryst. 2010, 66, 125-132. [CrossRef] 
51. Evans, P.R.; Murshudov, G.N. How good are my data and what is the resolution? Acta Cryst. D. Biol. Cryst. 2013, 69, 1204-1214. [CrossRef]

52. Keegan, R.M.; Winn, M.D. MrBUMP: An automated pipeline for molecular replacement. Acta Cryst. D. Biol. Cryst. 2008, 64, 119-124. [CrossRef] [PubMed]

53. Murshudov, G.N.; Skubák, P.; Lebedev, A.A.; Pannu, N.S.; Steiner, R.A.; Nicholls, R.A.; Winn, M.D.; Long, F.; Vagin, A.A. REFMAC5 for the refinement of macromolecular crystal structures. Acta Cryst. D. Biol. Cryst. 2011, 67, 355-367. [CrossRef] [PubMed]

54. Emsley, P.; Lohkamp, B.; Scott, W.G.; Cowtan, K. Features and development of Coot. Acta Cryst. D. Biol. Cryst. 2010, 66, 486-501. [CrossRef] [PubMed]

(C) 2020 by the authors. Licensee MDPI, Basel, Switzerland. This article is an open access article distributed under the terms and conditions of the Creative Commons Attribution (CC BY) license (http://creativecommons.org/licenses/by/4.0/). 